\title{
The NAC side of the fruit: tuning of fruit development and maturation
}

\author{
Sara Forlani(iD, Chiara Mizzotti[D and Simona Masiero * (i)
}

\begin{abstract}
Fruits and seeds resulting from fertilization of flowers, represent an incredible evolutionary advantage in angiosperms and have seen them become a critical element in our food supply.

Many studies have been conducted to reveal how fruit matures while protecting growing seeds and ensuring their dispersal. As result, several transcription factors involved in fruit maturation and senescence have been isolated both in model and crop plants. These regulators modulate several cellular processes that occur during fruit ripening such as chlorophyll breakdown, tissue softening, carbohydrates and pigments accumulation.

The NAC superfamily of transcription factors is known to be involved in almost all these aspects of fruit development and maturation. In this review, we summarise the current knowledge regarding NACs that modulate fruit ripening in model species (Arabidopsis thaliana and Solanum lycopersicum) and in crops of commercial interest (Oryza sativa, Malus domestica, Fragaria genus, Citrus sinensis and Musa acuminata).
\end{abstract}

Keywords: Fruit, NAC, Ripening, Senescence, Transcription factor

\section{Background}

It is widely accepted that fruits play a key role in the evolutionary history of angiosperms [1,2]. Fruits protect seeds during their growth and development, as well as favour their dispersion, providing a remarkable evolutionary advantage [3]. At the same time, they are an essential nutritional component of our diet and one of the most important pillars of the world economy $[4,5]$. Therefore, studies regarding the formation and ripening of fruit are crucial to unveil the mechanisms at play during fruit development, as this may lead to possible applications in the optimization of yield, quality, and post-harvest storage.

Transcription factors regulate the expression of many genes in different tissues and are classified according to their functional domains and binding specificity [6]. Among their many targets, they regulate the

*Correspondence: simona.masiero@unimi.it

Department of Biosciences, Università Degli Studi Di Milano, Via Celoria 26, 20133 Milan, Italy transcription of genes involved in environmental stress response [7, 8], response to pathogens [9], and fruit ripening $[10,11]$ all of which impact proper fruit development and maturation. Many transcription factors are known to be involved in such processes, as example, the MADS-box (MCM1/AGAMOUS/DEFICIENS/SRF) transcription factor family counts numerous key players of fruit development and maturation [12], together with the MYB (MYeloBlastosis) [13, 14] and the AP2/ ERF (APETALA 2/Ethylene Response Factors) DNA binding proteins $[15,16]$. Beside these wide groups of transcription factors, smaller families also participate to the regulation of fruit development and ripening like SPL (SQUAMOSA promoter binding protein-like), TCP (TEOSINTE BRANCHED 1/CYCLOIDEA/PROLIFERATING4 CELL FACTORS) and Dof (DNA binding with one finger) proteins [17-19]. However, one of the largest and most famous groups of plant-specific transcription factors known to be involved in such processes is the NAC (NAM/ATAF1/CUC2) superfamily [20-23]. In the next paragraphs, we discuss the pivotal role of NAC 
transcription factors in fruit development and maturation, focusing not only on fruit model species (Arabidopsis thaliana and Solanum lycopersicum) but also on other relevant species.

\section{Synopsis of NAC transcription factors A plant-specific family}

NAC superfamily is a large group of plant-specific transcription factors whose name is an acronym of NAM, ATAF1,2, and CUC2, the first members characterized. NAM (No Apical Meristem) was characterized in Petunia $\mathrm{x}$ hybrida; in nam mutants, embryos fail to develop SAM (Shoot Apical Meristem), cotyledons are fused, and occasionally they display an abnormal number and distribution of organ primordia in flowers [24]. In Arabidopsis thaliana, CUC2 (Cup-Shaped Cotyledon) displays high homology with the NAM sequence. CUC2 acts redundantly with CUC1, and the double mutant cuc1 cuc2 fails to develop a SAM and its cotyledons are fused on both sides [25]. Arabidopsis Transcription Activator Factors (ATAF) are a subgroup of the NAC family which includes two of the first NAC proteins characterized, ATAF1 and 2 , as being involved in stress response and senescence $[26,27]$. For a deeper characterization of these transcription factors and their conserved structure, see below (paragraph 2.2 "NAC transcription factors' structure" and 3.1 "Arabidopsis fruit and NAC transcription factors").

Members of the NAC superfamily can be found in many different plant species (see Table S1). However, numbers and species are constantly increasing together with the improvement of genome annotations (see paragraph 3.3 "A constantly increasing number of species relies on NAC transcription factors"). In Table 1, we list the NAC transcription factors presented and discussed in the next paragraphs.

NAC family is one of the largest groups of transcription factors and they modulate several processes during a plant's lifetime (Fig. 1). They participate in various developmental programmes, such as the formation of shoot and root apical meristem during embryogenesis, interacting with homeotic proteins and establishing organ boundaries [29-35]. Some NAC transcription factors have also been shown to play a role in lateral root development [36, 37] and in flower formation [29]. They also regulate senescence processes in leaves and fruits [38-50].

NAC transcription factors mainly modulate the response to environmental stresses [51-58], such as drought stress [59-65] and salt stress [66, 67]. At the same time, NAC transcription factors also regulate the stress response triggered by pathogens [52, 55, 68-71]. Furthermore, they participate in fibre development [72, 73], and secondary cell wall deposition [74-79] through the binding of a NAC-specific sequence in the promoter of the target genes [80]. Among several other targets, NACs regulate MYB transcription factors involved in secondary cell wall and lignin biosynthesis. Further still, they target either, other NACs or enzymes involved in cell wall modification and programmed cell death [80, 81]. As important regulators of plant processes, NAC transcription factors respond to phytohormones [82] such as abscisic acid (ABA) [83], ethylene [84], cytokinins [85], jasmonic acid [86], gibberellins [87, 88], and auxin $[36,89]$.

Among all the regulatory processes they govern, NAC transcription factors also modulate fruit development and maturation. Hereby, a complete overview of the fruitrelated NACs, identified and characterized so far, will be provided.

\section{NAC transcription factors' structure}

The modular structure of NAC TFs is characterized by a highly conserved N-terminal NAC domain (of about 150 amino acids) and a C-terminal Transcription Regulatory Region (TRR) which is more divergent (Fig. 2) [90, 91]. The NAC domain is responsible for the DNA binding activity and it is divided into five subdomains A-E $[92,93]$. The subdomain $A$ is involved in the formation of functional dimers, while the $C$ and $D$ subdomains, which are highly conserved, contain several positively charged amino acids necessary to interact with the DNA. The $\mathrm{B}$ and $\mathrm{E}$ subdomains are divergent, and they might be responsible for the functional diversity of NAC genes [90, 94]. Putative Nuclear Localization Signals (NLS) have been detected in $\mathrm{C}$ and $\mathrm{D}$ subdomains, while the DNA Binding Domain (DBD) is a 60 amino acid region located within subdomains $D$ and $E$ [92, 93]. In many NAC proteins, the NLS is present at the N-terminal end, however, Mohanta and collaborators also described some NLS placed in the C-terminal region [23]. They also described NAC TFs that contain more than one NLS, as many as four NLS in a single NAC protein. The NLS is characterized by the presence of a cluster of positively charged amino acids, and NAC proteins can contain single or more than one cluster defining mono-, bi-, or multi-partite motifs [23].

The N-terminal DBD is also involved in the formation of homo- and/or hetero-dimers: NAC TFs can bind DNA as homo- or hetero-dimers and the dimerization is necessary for a DNA stable binding [20,95]. In soybean, it has been demonstrated that the D subdomain contains a hydrophobic Negative Regulatory Domain (NRD) to suppress the transcriptional activity [96]. Such a transcriptional repressor motif was recently identified in several plant species [23]. 
Table 1 NAC transcription factors described in this manuscript, listed in order of appearance

\begin{tabular}{|c|c|c|c|}
\hline Species & NACTF & $\begin{array}{l}\text { Gene ID/Genbank } \\
\text { reference number }\end{array}$ & Main function in fruit \\
\hline Arabidopsis thaliana & NARS1/ANAC056/NAC2 & AT3G15510 & Embryogenesis and silique senescence \\
\hline Arabidopsis thaliana & NARS2/ANAC018/NAM & AT1G52880 & Embryogenesis and silique senescence \\
\hline Arabidopsis thaliana & AtNAP/ANAC029 & AT1G69490 & Silique senescence \\
\hline Arabidopsis thaliana & ANAC058 & AT3G18400 & Silique senescence \\
\hline Arabidopsis thaliana & AtJUB1/ANAC042 & AT2G43000 & Silique growth \\
\hline Solanum lycopersicum & NOR & Solyc10g006880 & Ethylene biosynthesis, carotenoid accumulation, fruit softening \\
\hline Solanum lycopersicum & NOR-likel/SINAC3/SNAC4/SINAC48 & Solyc07g063420 & $\begin{array}{l}\text { Seed development, carotenoid accumulation, ethylene biosyn- } \\
\text { thesis, fruit softening }\end{array}$ \\
\hline Solanum lycopersicum & SINACI/SINAC033 & Solyc04g009440 & Fruit softening, pigmentation \\
\hline Solanum lycopersicum & SIOREISO2 & Solyc02g088180 & Fruit senescence, sugar accumulation \\
\hline Solanum lycopersicum & SINAP2/SNAC9/SINAC19 & Solyc04g005610 & Sugar and carotenoid accumulation, ethylene production \\
\hline Oryza sativa & OsNACO2O & Os01g01470 & Grain size and weight \\
\hline Oryza sativa & OsNACO23 & Os02g12310 & Grain size and weight \\
\hline Oryza sativa & OsNAC026 & Os01g29840 & Grain size and weight \\
\hline Oryza sativa & ONAC127 & Os11g31340 & Starch accumulation, carbohydrate transport \\
\hline Oryza sativa & ONAC129 & Os11g31380 & Starch accumulation, carbohydrate transport \\
\hline Malus domestica & MdNAC1 & $103,451,803$ & Ethylene signalling, ABA biosynthesis \\
\hline Malus domestica & MdNAC2 & $103,446,449$ & Ethylene signalling \\
\hline Malus domestica & MdNAC47/MdNAC63 & MG099900 & Ethylene production \\
\hline Malus domestica & NAC18.1 & $103,436,128$ & Fruit softening, harvest date \\
\hline Malus domestica & MdNAC52 & MG099889 & Anthocyanin accumulation \\
\hline Malus domestica & MdNAC042 & 818,902 & Anthocyanin accumulation \\
\hline Fragaria $\times$ ananassa & FaNACOO6 & FvH4_1g27900 & Fruit softening \\
\hline Fragaria $\times$ ananassa & FaNAC021 & FvH4_3g04630 & Fruit softening \\
\hline Fragaria $\times$ ananassa & FaNAC022 & FvH4_3g08490 & Fruit softening \\
\hline Fragaria $\times$ ananassa & FaNAC035 & FvH4_3g20700 & Fruit softening, pigment and sugar accumulation \\
\hline Fragaria $\times$ ananassa & FaNAC042 & FvH4_4g23130 & Fruit softening \\
\hline Fragaria $\times$ ananassa & FaNAC092 & FvH4_6g48120 & Fruit softening \\
\hline Fragaria chiloensis & FCNAC1 & KP966107 & Cell wall remodelling \\
\hline Citrus sinensis & CitNAC62 & Ciclev10019368m & Lowering of citric acid content \\
\hline Citrus sinensis & CsNAC & EF596736 & Response to citrus peel pitting \\
\hline Musa acuminata & MaNAC1/MaNAC087 & Achr6T27000 & Ethylene signalling \\
\hline Musa acuminata & MaNAC2/MaNACO92 & Achr6T31585 & Ethylene signalling \\
\hline Musa acuminata & MaNAC3 & Achr9T27530 & Ethylene signalling \\
\hline Musa acuminata & MaNAC4 & Achr7T00860 & Ethylene signalling \\
\hline Musa acuminata & MaNAC5/MaNAC140 & Achr9T26140 & Ethylene signalling, response to biotic stress \\
\hline Musa acuminata & MaNAC6 & Achr11T00880 & Ethylene signalling \\
\hline
\end{tabular}

${ }^{\mathrm{a}}$ ID as reported in [28]

At the C-terminal, the presence of several group-specific motifs in the TRR allow the activation or repression of the transcription [23]. Its divergence determines the function of each NAC protein and modulates the interaction between NAC TFs and their target proteins. Welner and collaborators [95] suggested that NAC genes present a conserved consensus sequence for specific DNA recognition that increases DNA binding affinity. Recently, this consensus sequence was detected in 160 plant species [23].

Several NACs possess a transmembrane domain; it can be located at both the terminal ends of the proteins but were prominently found at the C-terminal end [23].

In 2004, Ernst and collaborators solved the NAC domain's structure of ANAC019 by X-ray crystallography [90]. Some years later, Chen and collaborators 


\section{Response to environmental stresses: drought stress, salt stress and pathogens. [51-71]}

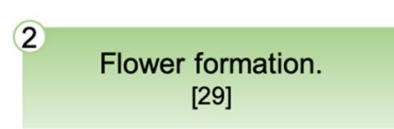

\section{Establishing organ boundaries. [29-35]}

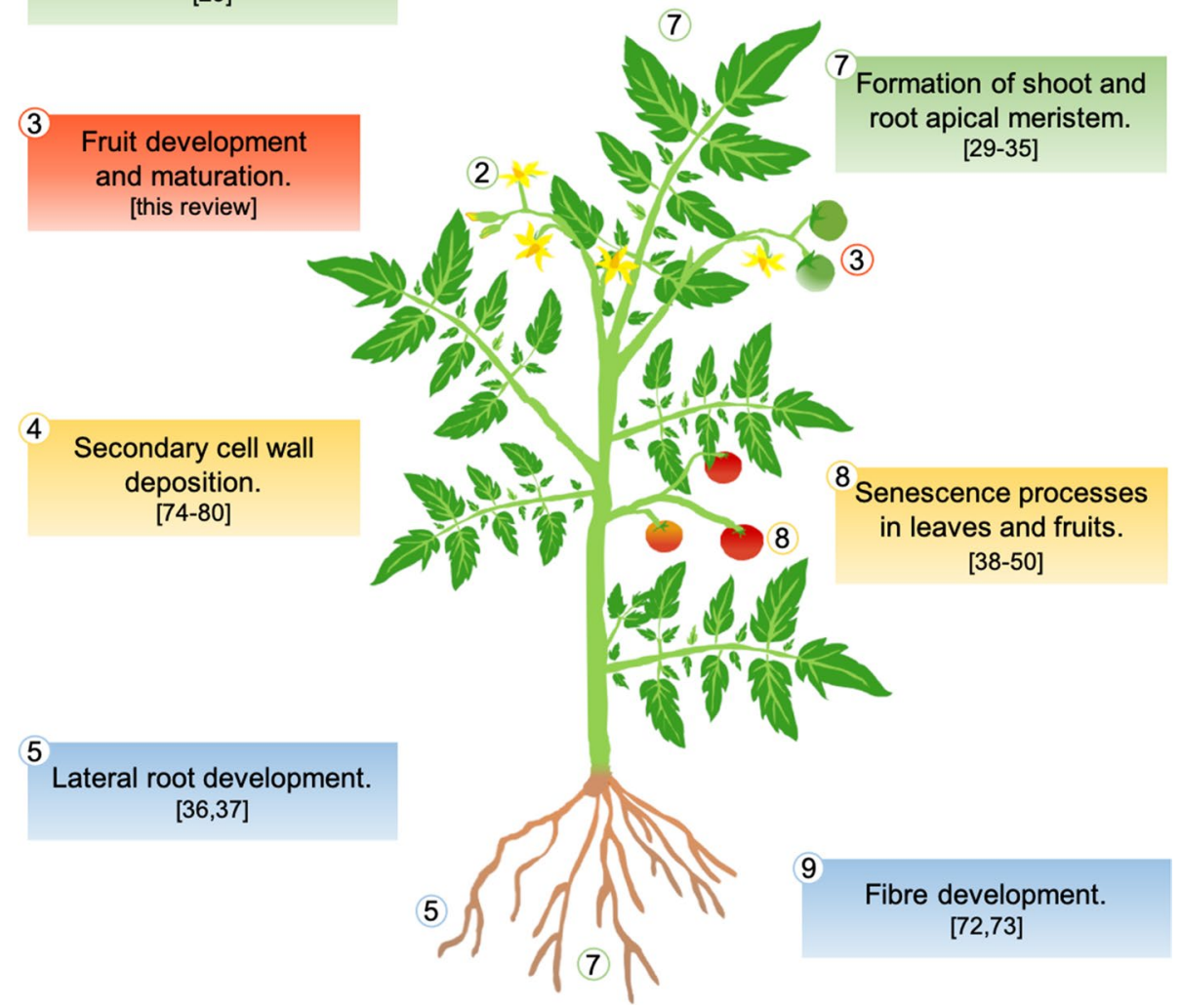

Fig. 1 NACs play a role in numerous processes during a plant's lifecycle, summarized in the figure using Solanum lycopersicum as representative plant. Each box represents a process, significant examples of NAC TFs involved are reported as references between brackets

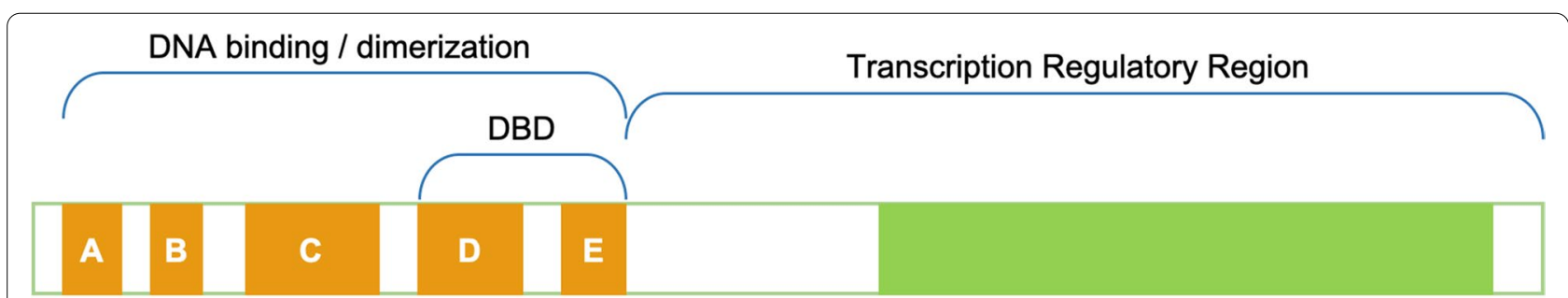

NAC domain

Activation domain

Fig. 2 Structural domains and subdomains of NACTFS 
determined the crystal structure of the NAC domain of the STRESS-RESPONSIVE NAC1 (SNAC1) protein in rice [94]. The NAC domain consists of a twisted antiparallel $\beta$-sheet, used for DNA binding, packed between an $\mathrm{N}$-terminal $\alpha$-helix on one side and a short helix on the other [90]. Several amino acids located in subdomains C, $\mathrm{D}$ and $\mathrm{E}$ were identified as having biochemical functions crucial for DNA binding [90, 91, 94].

The sequence of the NAC binding site has been addressed with several techniques (X-ray, SELEX, EMSA, footprint, PBM, ChIP). The binding site contains the CGT[AG] core motif, and the flanking sequences are involved in the determination of the target promoter binding affinity and specificity (for a review see [97]).

\section{Same family, different species}

The NAC superfamily includes only plant-specific transcription factors, widespread in an increasing number of species. First, we will focus on model species, such as Arabidopsis thaliana and Solanum lycopersicum, for their role as reference plants in studies focused on fruit development, ripening and senescence [98].

\section{Arabidopsis thaliana siliques and NAC transcription factors}

The first NACs described as regulators of fruit senescence were NARS1 and NARS2 (NAC-REGULATED SEED MORPHOLOGY1 and -2, also known as ANAC056/NAC2 and ANAC018/NAM, respectively). NARS1 and NARS2 regulate embryogenesis, through the control of ovule integument development and degeneration, seed morphogenesis, and silique senescence [99]. While the single mutants do not show any phenotype, the double mutant nars 1 nars 2 has delayed silique senescence. Currently, no molecular data are available regarding NARS1 and/or NARS2's involvement in hormonal signal pathways. It has been shown that NARS1 and/or NARS2 work to ease an intracellular environment triggered by programmed cell death in the integument, and similarly could also occur in the silique. Recently, Ma and colleagues [50] proposed NARS1 and NARS2 as NOR (NONRIPENING) homologs. NOR is a NAC transcription factor involved in tomato fruit ripening (see below, [100]). However, on the basis of their expression pattern and their phenotype, Ma and co-workers [50] concluded that NARS1 and NARS2 act differently from NOR. Indeed, while NARS1 and NARS2 are expressed in aging leaves, as well as in ripening fruits, in nars1 nars 2 mutant senescence was delayed only in siliques, while no effect was observed in leaves. This suggests a different mode of action compared to NOR.

AtNAP (NAC-LIKE, ACTIVATED BY AP3/PI, $A N A C 029)$ was initially described as promoter of leaf senescence [38], but was later shown to promote silique maturation as well [43]. Indeed, AtNAP messenger accumulates with fruit maturation progression and atnap siliques delay senescence by $4-5$ days. Moreover, the ethylene and respiratory surges are decoupled, and exogenous ethylene treatments cannot anticipate the respiratory surge [43]. Few genes, whose products participate in ethylene biosynthesis, perception, and signal transduction pathways, were downregulated in atnap mutant. However, it is still not clear how the changes in the expression of these genes could affect the senescence in mutant plants. AtNAP might be NOR orthologue, but such conclusion is not fully supported [43].

The role of few other Arabidopsis NAC proteins has been described in siliques, among them NAC058 which represses silique senescence. In the nac058 knock-down mutant the maturation of the fruit is precocious as demonstrated by the premature yellowing, the reduced chlorophyll content and the reduced photosynthetic performance [101].

JUNGBRUNNEN1 (JUB1/ ANAC042) is not involved in the maturation process rather in the growth of the silique. The silique of plants that overexpress JUB1 are shorter than normal, but it is interesting to report that in tomato the overexpression of $A t J U B 1$ delays fruit ripening by 6 days $[87,88]$. The overexpression of AtJUB1 in tomato represses several ethylene-related ripening genes such as ACS (ACC synthase) and ACO (ACC oxidase, [88]). In Arabidopsis and in tomato, AtJUB1 represses the transcription of GA3ox1 (GA 3-oxidase1) and DWF4 (DWARF4), genes important for gibberellin (GA) and brassinosteroid (BR) biosynthesis, thus phenocopying GA and BR deficiency. AtJUB1 also directly represses PIF4 (PHYTOCHROME INTERACTING FACTOR4), a positive regulator of cell elongation, and activates the $D E L L A$ genes, repressors of cell proliferation and expansion $[87,88]$.

\section{Tomato fruit and their NAC transcription factors}

The complete sequencing of the tomato genome [102] provided a fundamental tool for the prediction and identification of numerous genes. 104 SlNAC genes have been identified so far [103], mapping to all 12 chromosomes.

The nor mutant fails to produce the climacteric peak of ethylene, thereby causing an arrested ripening [100, 104] which cannot be rescued by exogenous application of ethylene [105, 106]. Positional cloning demonstrated that NOR encodes a NAC transcription factor $[105,106]$. Another spontaneous allele of NOR is alcobaca (alc) found in the Penjar tomatoes which have a very long shelf life $[107,108]$. The alc allele is weaker compared to nor, but its ripening delay is comparable to the newer nor alleles that have been recently obtained using the CRISPR-Cas9 methodology [108-111]. All these alleles are caused by amorphic mutations, and mutant plants display milder 
phenotypes compared to the classical nor mutant, that is actually a gain-of-function [111-113]. Similar results have also been obtained with CRISPR null alleles of other tomato transcription factors involved in fruit maturation, such as RIN and CNR [111]. RIN encodes a MADS-box transcription factor $[114,115]$ that directly binds NOR promoter [116-118]. However, Wang and collaborators [111] have recently suggested that such transcription factors might act redundantly in a complex network that integrates multiple signals, more so than being master regulators alone. Indeed, their effect on ethylene production, lycopene accumulation and other ripening traits has been shown to be quantitative and additive [119]. Moreover, although both NOR and RIN play a role in fruit senescence, only NOR has been found involved in the mediation of pathogen susceptibility in ripening fruit [120].

Some NAC transcription factors, able to influence fruit development and maturation, were initially classified as stress-responsive genes, and for this reason NAC genes are often referred to using different names, complicating literature data screenings [121]. NOR-like1 was originally identified as $S I N A C 3$, a negative regulator of drought stress under the control of ABA [122]. Later, analysing RNA interference lines, SINAC3 was revealed to be essential for appropriate embryo and endosperm development in seeds [123]. Polygalacturonase-2 (PG-2) was eventually isolated as one of SINAC3's direct targets through co-immunoprecipitation assays [124]. At the same time, Zhu and collaborators also referred to NORlike1 as SNAC4 (SINAC48), identifying it as regulator of salt stress and drought tolerance [125]. It shares $49.2 \%$ of nucleotide sequence with NOR and its disruption causes a decrease in carotenoid accumulation, chlorophyll breakdown and ethylene biosynthesis [126]. Moreover, NOR-like1 can bind directly both RIN and NOR, suggesting that it could act upstream of these ripening regulators, and its predicted tertiary structure reveals a high degree of similarity with ANAC072, involved in chlorophyll degradation during leaf senescence [126-128]. Recently, NOR-like1 has been shown to directly bind the promoter of genes involved in ethylene production, fruit firmness and colour change [129].

Tweneboah and $\mathrm{Oh}$ [55] summarized the stress-related NAC transcription factors in different Solanaceae and, as pointed out previously, some of them participate in fruit development and ripening. As an example, SINAC1 (also known as SINAC033) participates in heat and chilling tolerance $[130,131]$ and defence against Pseudomonas syringae [132], thus modulating biotic and abiotic stress responses. SINAC1 binds the regulatory regions of genes related to ethylene or lycopene biosynthesis [133] and its suppression or overexpression can alter fruit softening and pigmentation $[133,134]$.
SlORE1S02, SlORE1S03, and SIORE1SO6 are the orthologues of the Arabidopsis ORESARA1 (ORE1/NAC092) [135]. ORESARA means "long-living" in Korean; indeed, the ore1 mutant delays leaf senescence in Arabidopsis [136]. SlORE1S02, SlORE1SO3, SlORE1SO6 and ORE1 are all regulated by the microRNA miR164. In tomato, they are expressed in leaves where their overexpression accelerates senescence. The reduction of SIORE1SO2 via RNAi interference leads to increased carbon assimilation, consequently transgenic plants show a higher harvest index with no consequences on fruit size. Transgenic fruit delay senescence and also accumulate more soluble solids in ripe fruit [135].

SINAP2 impacts fruit yield and metabolism, since its inhibition causes fruits to retain more sugars [83]. This transcription factor is structurally similar to AtNAP (described in the previous paragraph [43]). Kou and co-workers [127] described SINAP2 naming it SNAC9 (SlNAC19). Fruit of slnac19 exhibit a reduced carotenoid content and ethylene production [137]. The same phenotype has been observed in nor-like1 fruits, but they accumulate more ABA than SINAC19 ones [137]. SINAP2 modulates NOR expression [50] and, together with NOR and NOR-like1, it is considered one of the key tomato ripening regulators [138].

\section{A constantly increasing number of species relies on NAC transcription factors}

Beside model species for dry and fleshy fruits, NAC transcription factors have been identified and analysed in many other species of commercial interest. Here are listed the most recent findings in a few select species. We will review their role in Oryza sativa, Malus domestica, Fragaria genus, Citrus sinensis and Musa acuminata.

\section{Rice (Oryza sativa)}

Although grains do not resemble the classic idea of fruit, they are actually composed of fruit coat strongly bound to the seed coat, and they enclose the germ and the endosperm. This non-canonical one-seeded fruit is produced by cereals, such as rice, barley and wheat, and it is called caryopsis.

One of the most widely cultivated cereals is rice, and for this reason it represents the topic of many researches. In rice, NAC transcription factors are involved in biotic and abiotic stress [52, 139]. OsNAC020, OsNACO23 and OsNACO26 have been identified as grain-specific conserved NAC genes in rice [140]. Indeed, previous studies on OsNAC020, OsNACO23 and OsNACO26 detected a higher expression in caryopsis [141]. Moreover, OsNAC020 and OsNAC023 can dimerize with 
OsNAC026 and localize in the nucleus to regulate genes involved in seed size and weight [142].

Since rice seeds are mostly intended for human consumption, their composition is one of the principle features to be considered. ONAC127 and ONAC129 are expressed in caryopsis and the corresponding gene products regulate starch accumulation and genes related to carbohydrates transport during grain filling [143].

Another important commercial feature is the grain yield, determined by numerous factors, e.g. resistance to drought stress and shoot branching. Overexpression of OsNAC5, OsNAC9 and OsNAC10 causes changes in root diameter and architecture leading to increased drought tolerance and grain yield [144-146]. Similarly, OsNAP and SNAC1 overexpression leads to a greater seed production in restricted water conditions $[147,148]$. However, it is interesting to note that not all the NAC transcription factors involved in drought stress mitigation can increase the grain yield, as for ONAC022 [149]. Shoot branching can eventually influence grain yield. For example, OsNAC2 regulates shoot branching [150] and plant height [151]. OsNAC2 is negatively regulated by $m i R 164 b$; if the sequence is mutated to be resistant to miR164b, the final grain number increases [152].

\section{Apple (Malus domestica)}

In the apple cultivar "Golden delicious", Wang and Xu [153] found that MdNAC1 and MdNAC2 interact and are co-expressed, respectively, with the ethylene receptors MdRTE1a (Malus domestica REVERSION-TO-ETHYLENE SENSITIVITY1a) and MdRTE1b. This pinpoint a possible involvement in pome growth and ripening. Later, $M d N A C 1$ was also found to be responsible for plant height and drought tolerance, since its overexpression leads to a dwarf phenotype [154] with reduced water loss and a stable photosynthetic rate [155]. Moreover, Jia and co-workers hypothesized that $M d N A C 1$ controls the biosynthesis of ABA [154].

NAC transcription factors mediate ethylene and auxin crosstalk in apple, especially when the production of ethylene is impaired [156], as already suggested in Arabidopsis [91].

Zhang and collaborators [157] found that 13 NAC genes are differentially expressed in numerous tissues during fruit growth and ripening. The evaluation of their response to $1-\mathrm{MCP}$ treatment and ethylene exposure indicates that NACs could regulate pome development in both an ethylene-dependent and independent manner. The mediation of ethylene signalling was further confirmed by MdNAC47, which directly binds the positive regulator of ethylene biosynthesis MdERF3 (Malus domestica ETHYLENE RESPONSE FACTOR), modulating salt stress tolerance [158]. MdNAC47 was so called since it was thought to be the orthologue of Arabidopsis ANAC047, however its genomic locus has been recently annotated as MdNAC63 [159].

Fruit firmness, an important trait in post-harvest conservation, is also controlled by NAC transcription factors. In particular, the NAC18.1 protein displays high similarity with tomato NOR, and could be a major determinant of fruit softening and harvest date [160, 161]. Another process typical of the ripening of fleshy fruits is the accumulation of flavonoids such as anthocyanins, which give the fruit colour to attract frugivorous animals [162]. MdNAC52 overexpression leads to anthocyanin accumulation in apple calli and it can induce the expression of $M d M Y B 9$ and $M d M Y B 11$, regulating proanthocyanidin biosynthesis [163]. Recently, MdNAC042 was also discovered to positively correlate with anthocyanin content in red apples, regulating pigmentation through dimerization with MdMYB10 [164].

\section{Strawberry (Fragaria genus)}

112 NAC genes have been identified in the commercial strawberry (Fragaria $x$ ananassa), thanks to the comparison with the woodland strawberry (Fragaria vesca) genome [165]. Six of them are associated with fruit ripening and senescence: FaNACOO6, FaNAC021, FaNAC022, FaNAC035, FaNAC042, FaNAC092. Their expression pattern correlates with anthocyanin biosynthesis [166] and their products play a role in tissue softening [167]. Recently, FaNAC035 was demonstrated to regulate ripening by controlling fruit softening and pigment and sugar accumulation. Moreover, it regulates ABA biosynthesis and signalling and cell wall degradation and modification [168].

FaNAC087 and FaNACO38 are negatively modulated by miRNA164 [169], as happens in Arabidopsis thaliana with ORE1 [170]. Since FaNAC087 and FaNAC038 increase their expression in the last stages of ripening [169], $\mathrm{Li}$ and co-workers [171] analysed their regulation in post-harvest storage conditions, confirming the negative correlation between miRNA164 and its NAC messenger targets. The role of sRNAs as regulators of post-harvest shelf life has been recently corroborated, highlighting that NAC and other families of transcription factors represent important targets [172].

The commercial strawberry (Fragaria $x$ ananassa) was obtained by crossing the parental species Fragaria chiloensis and Fragaria virginiana. Due to great interest in its limited post-harvest period, transcription factors involved in fruit ripening regulation and cell wall remodelling have been characterized in Fragaria chiloensis, including NAC TFs. Among them, FcNAC1 which interacts with FCPL (Fragaria chiloensis pectin lyase), contributing to cell wall remodelling [173]. 


\section{Orange (Citrus sinensis)}

Given the economic and nutritional importance of sweet orange, the discovery of the regulators of fruit quality and duration have always been an essential goal to reach. In orange, transcription factors belonging to the NAC superfamily represent one of the key elements of these processes. NAC genes differentially expressed between a late-ripening mutant and a wild type variety of sweet orange have been identified [174], among them NAC61, NAC74, NAC84 and RD26 (RESPONSIVE TO DESICCA$T I O N$ 26). In particular, $R D 26$ displays high correlation with fructose and glucose accumulation; the Arabidopsis orthologue RD26/ANAC072 is a transductor of the ABA signal [175] and activates the expression of genes whose products participates in chloroplast protein degradation during leaf senescence [176].

CitNAC is expressed in peel and pulp during orange fruit ripening and is phylogenetically similar to AtNAP [177]. This suggests the possible involvement of CitNAC in sweet orange fruit development and senescence.

In order to lower the citric acid content in mature fruit, CitNAC62 acts in a synergic way with CitWRKY1 modulating CitAco3, an aconitate hydratase involved in the catabolism of citric acid [178].

As in tomato, stress-related NAC transcription factors play an active role in determining fruit quality, thus influencing the postharvest conservation. Fan and co-workers [179] point out that CsNAC, the orthologue of Arabidopsis ATAF1, participates to citrus peel pitting, a disorder that affects the quality and the economic value of citrus fruits. NAC transcription factors are also involved in the response to cold storage, probably increasing the anthocyanin content [180]. Mitalo and collaborators [181] have found that the NAC superfamily participates in transcriptional cascades whose products help to counteract citrus greening, a destructive disease for citrus fruits (Bove, 2006). They may also be involved in a similar resistance process in lemon fruit [181]. In particular, $N A C-1$ and $R D 26$ transcripts are detected during the symptomatic and asymptomatic phases of citrus greening [182]. In addition, many other citrus NAC transcription factors involved in response to multiple stresses have been found [183]. However, further studies are required to unveil their role in the determination of fruit quality and proper development.

\section{Banana (Musa acuminata)}

Studies on NAC superfamily in banana started with the prediction of loci potentially coding for such transcription factors, and the definition of orthologous groups comparing sequences from monocots and dicots [28]. Recent works implemented the previous findings, identifying 181 NACs mapped in all the 12 chromosomes
[184]. 10 MaNACs were associated with ripening in ethylene-treated banana fruits, some of them carrying ethylene responsive elements in their promoter. Six of them (MaNAC1 to MaNAC6) have already been previously characterized as part of the ethylene mediated fruit ripening [185]. MaNAC1 (MaNAC087) is known for its role in both stress tolerance and fruit maturation, it is induced after cold stress and physically interacts with cold signalling pathway elements [185]. Moreover, MaNAC1 interacts with MaEIL5 (Musa acuminata ETHYLENE INSENSITIVE 3-like 5), a downstream component of the ethylene signalling pathway [186]. MaNAC2 (MaNAC092), like MaNAC1, directly interacts with MaEIL5 and its expression is upregulated by ethylene both in the peel and pulp of banana fruit [186]. Additionally, the expression of MaNAC1 and MaNAC2, together

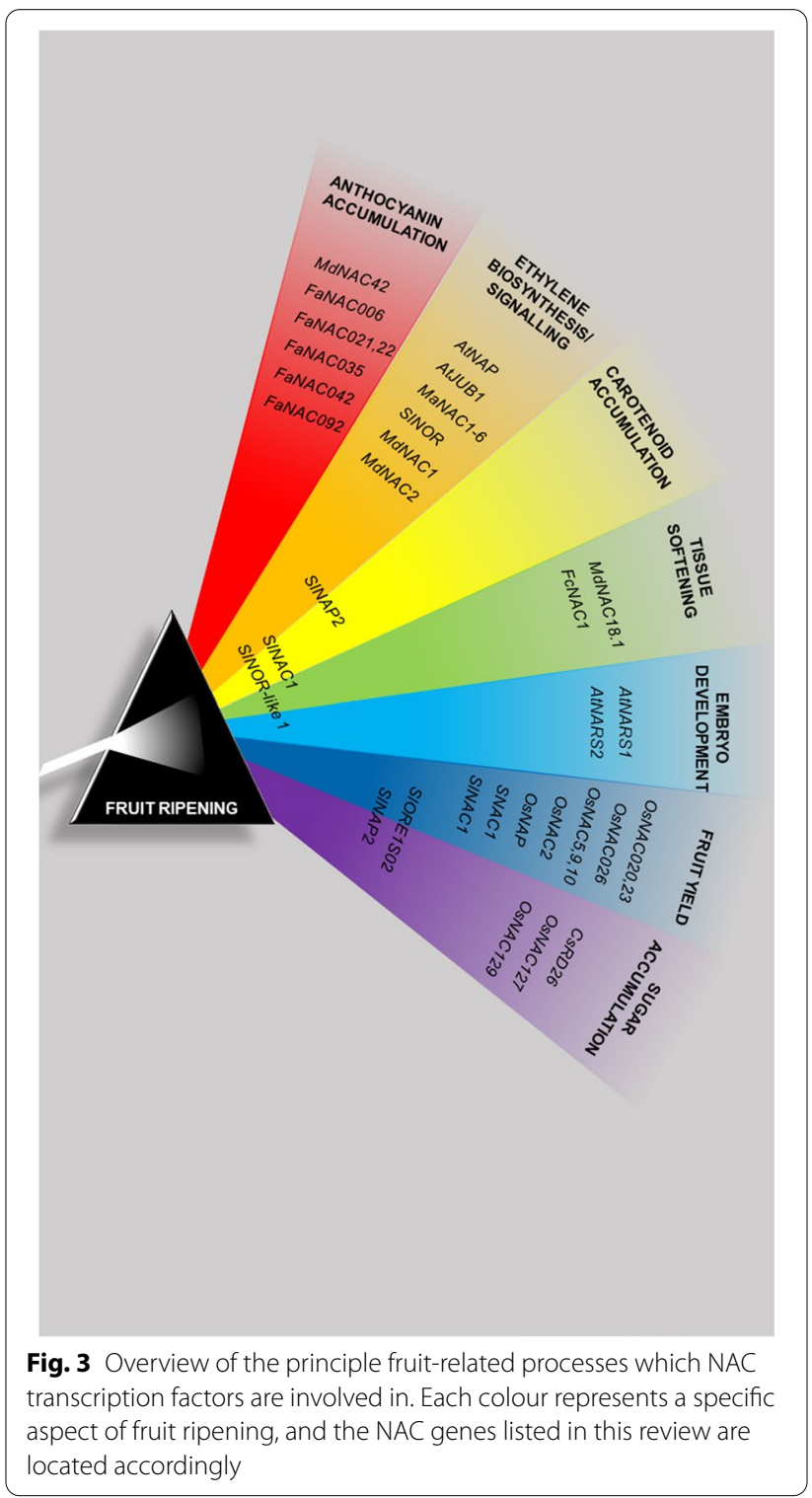


with MaNAC5 (MaNAC140), is upregulated in fruit after infection with Colletotrichum musae [187]. Furthermore, MaNAC5 can interact with WRKY transcription factors and activate pathogenesis-related genes to counteract the disease [187]. Other NAC transcription factors characterized so far in banana play a role in leaves senescence [188] or drought stress [189, 190]. Further studies are necessary to deepen the role of NAC superfamily in banana fruit ripening.

\section{Conclusions}

The economic and dietary relevance of fruit is an important stimulus to explore fruit maturation and senescence in non-model species. In respect to fruit maturation, a pivotal role is played by NAC transcription factors and therefore they are proposed as interesting targets to modulate development and ripening, and to prolong fruit shelf life. In this work we provide a synopsis of the fruit-related NAC transcription factors identified in model species and in major crop species (Fig. 3). The processes of maturation and ripening must be fine-tuned to ensure the protection of growing seeds and the correct release of offspring. For this reason, they are regulated by a network of interconnected transcription factors belonging to different families.

Unfortunately, the non-model species have yet to be deeply investigated but, from the data available, it is clear that NAC transcription factors represent a conserved family necessary for the regulation of fruit development, maturation and post-harvest life. Due to their ubiquitous presence in numerous species, unveiling NAC TF regulation network could represent a potential tool for the regulation of post-harvest fruit conservation and pathogen resistance in economically relevant species. Within this view, as suggested by Singh and collaborators [191], future researches could focus on the analysis of redundancy among these TFs, in order to identify pivotal players in the regulation of fruit maturation.

In parallel, the identification of NAC interactors could reveal potential inhibitors or enhancers of their activity, helping the conservation and response to pathogens in commercial fruits.

\begin{abstract}
Abbreviations
ABA: Abscisic acid; DBD: DNA Binding Domain; NAC: NAM/ATAF/CUC; NLS: Nuclear Localization Signal; NRD: Negative Regulatory Domain; SAM: Shoot Apical Meristem; TF: Transcription factor; TRR: Transcription Regulatory Region.
\end{abstract}

\section{Supplementary Information}

The online version contains supplementary material available at https://doi. org/10.1186/s12870-021-03029-y.

Additional file 1: Table S1. Number of NAC transcription factors identified in several plant species.

\section{Acknowledgements}

We thank James Friel for critical reading of the manuscript. The authors acknowledge support from the University of Milan through the APC initiative. We apologize to all the researchers whose work could not be cited due to space limitations.

\section{Authors' contributions}

SF, CM and SM wrote the review. All authors have read and approved the final manuscript.

\section{Funding}

The work has been supported by Ministero dell'Istruzione, dell'Università e della Ricerca (PRIN ISIDE, grant no. 2015BPM9H3_005 and PRIN Micromolecule, grant no. 20173LBZM2) to SM and by a fellowship from the Università degli Studi di Milano to SF. The funders had no role in the experimental design, data collection and analysis or writing of the manuscript.

Availability of data and materials

Not applicable.

\section{Declarations}

Ethics approval and consent to participate

Not applicable.

Consent for publication

Not applicable.

Competing interests

The authors declare that they have no competing interests.

Received: 26 October 2020 Accepted: 10 May 2021

Published online: 27 May 2021

\section{References}

1. Lorts CM, Briggeman T, Sang T. Evolution of fruit types and seed dispersal: a phylogenetic and ecological snapshot. J Syst Evol. 2008:46:396-404.

2. Knapp S, Litt A. Fruit-an angiosperm innovation. In: The molecular biology and biochemistry of fruit ripening. Oxford: Blackwell Publishing Ltd.; 2013. p. 21-42. https://doi.org/10.1002/9781118593714.ch2.

3. Knapp S. Tobacco to tomatoes: a phylogenetic perspective on fruit diversity in the Solanaceae. J Exp Bot. 2002;53:2001-22. https://doi.org/ 10.1093/jxb/erf068.

4. Wallace TC, Bailey RL, Blumberg JB, Burton-Freeman B, Chen CO, Crowe-White KM, et al. Fruits, vegetables, and health: a comprehensive narrative, umbrella review of the science and recommendations for enhanced public policy to improve intake. Crit Rev Food Sci Nutr. 2019;60:2174-211. https://doi.org/10.1080/10408398.2019.1632258.

5. Mason-D'Croz D, Bogard JR, Sulser TB, Cenacchi N, Dunston S, Herrero $M$, et al. Gaps between fruit and vegetable production, demand, and recommended consumption at global and national levels: an integrated modelling study. Lancet Planet Health. 2019;3:e318-29. https:// doi.org/10.1016/S2542-5196(19)30095-6.

6. Yamasaki K, Kigawa T, Seki M, Shinozaki K, Yokoyama S. DNA-binding domains of plant-specific transcription factors: structure, function, and evolution. Trends Plant Sci. 2013;18:267-76. https://doi.org/10.1016/j. tplants.2012.09.001.

7. Joshi R, Wani SH, Singh B, Bohra A, Dar ZA, Lone AA, et al. Transcription factors and plants response to drought stress: current understanding and future directions. Front Plant Sci. 2016;7(July):1-15.

8. Khan S, Li M, Wang S, Yin H. Revisiting the role of plant transcription factors in the battle against abiotic stress. Int J Mol Sci. 2018;19:1-29.

9. Amorim L, Santos R, Neto J, Guida-Santos M, Crovella S, Benko-Iseppon A. Transcription factors involved in plant resistance to pathogens. Curr Protein Pept Sci. 2017;18:335-51. 
10. Chen G, Alexander L, Grierson D. Constitutive expression of ElL-like transcription factor partially restores ripening in the ethylene-insensitive $\mathrm{Nr}$ tomato mutant. J Exp Bot. 2004;55:1491-7.

11. Ito Y. Regulation of tomato fruit ripening by MADS-box transcription factors. Jpn Agric Res Q. 2016;50:33-8.

12. Sharma D, Koul A, Kaul S, Dhar MK. Tissue-specific transcriptional regulation and metabolite accumulation in tomato (Solanum lycopersicum L.). Protoplasma. 2020;257:1093-108. https://doi.org/10.1007/ s00709-020-01492-2.

13. Cao H, Chen J, Yue M, Xu C, Jian W, Liu Y, et al. Tomato transcriptional repressor MYB70 directly regulates ethylene-dependent fruit ripening. Plant J. 2020;104:1568-81. https://doi.org/10.1111/tpj.15021.

14. Fu C, Chen H, Gao H, Lu Y, Han C, Han Y. Two papaya MYB proteins function in fruit ripening by regulating some genes involved in cell-wall degradation and carotenoid biosynthesis. J Sci Food Agric. 2020;100:4442-8. https://doi.org/10.1002/jsfa.10484.

15. Wu J, Fu L, Yi H. Genome-wide identification of the transcription factors involved in citrus fruit ripening from the transcriptomes of a lateripening sweet orange mutant and its wild type. 2016. https://doi.org/ 10.1371/journal.pone.0154330.

16. Gao J, Zhang Y, Li Z, Liu M. Role of ethylene response factors (ERFs) in fruit ripening. Food Qual Saf. 2020;4:15-20. https://doi.org/10.1093/ fqsafe/fyz042.

17. Khaksar G, Sangchay W, Pinsorn P, Sangpong L, Sirikantaramas S. Genome-wide analysis of the Dof gene family in durian reveals fruit ripening-associated and cultivar-dependent Dof transcription factors. Sci Rep. 2019;9:12109. https://doi.org/10.1038/s41598-019-48601-7.

18. Xie YG, Ma YY, Bi PP, Wei W, Liu J, Hu Y, et al. Transcription factor FvTCP9 promotes strawberry fruit ripening by regulating the biosynthesis of abscisic acid and anthocyanins. Plant Physiol Biochem. 2020;146:37483. https://doi.org/10.1016/j.plaphy.2019.11.004.

19. Xu Y, Xu H, Wall MM, Yang J. Roles of transcription factor SQUAMOSA promoter binding protein-like gene family in papaya (Carica papaya) development and ripening. Genomics. 2020;112:2734-47.

20. Olsen AN, Ernst HA, Leggio LL, Skriver K. DNA-binding specificity and molecular functions of NAC transcription factors. Plant Sci. 2005;169:785-97.

21. Nakashima K, Takasaki H, Mizoi J, Shinozaki K, Yamaguchi-Shinozaki K. NAC transcription factors in plant abiotic stress responses. Biochim Biophys Acta - Gene Regul Mech. 2012;1819:97-103. https://doi.org/10. 1016/j.bbagrm.2011.10.005.

22. Puranik S, Sahu PP, Srivastava PS, Prasad M. NAC proteins: Regulation and role in stress tolerance. Trends Plant Sci. 2012;17:369-81. https:// doi.org/10.1016/j.tplants.2012.02.004.

23. Mohanta TK, Yadav D, Khan A, Hashem A, Tabassum B, Khan AL, et al. Genomics, molecular and evolutionary perspective of NAC transcription factors. 2020. https://doi.org/10.1371/journal.pone.0231425.

24. Souer E, Van Houwelingen A, Kloos D, Mol J, Koes R. The no apical Meristem gene of petunia is required for pattern formation in embryos and flowers and is expressed at meristem and primordia boundaries. Cell. 1996;85:159-70.

25. Aida M, Ishida T, Fukaki H, Fujisawa H, Tasaka M. Genes Involved in organ separation in arabidopsis: an analysis of the cup-shaped cotyledon mutant. Plant Cell. 1997;9:841-57.

26. Christianson JA, Dennis ES, Llewellyn DJ, Wilson IW. ATAF NAC transcription factors: regulators of plant stress signaling. Plant Signal Behav. 2010:5:428-32.

27. Garapati P, Xue GP, Munné-Bosch S, Balazadeh S. Transcription factor ATAF1 in arabidopsis promotes senescence by direct regulation of key chloroplast maintenance and senescence transcriptional cascades. Plant Physiol. 2015;168:1122-39. https://doi.org/10.1104/pp.15.00567.

28. Cenci A, Guignon V, Roux N, Rouard M. Genomic analysis of NAC transcription factors in banana (Musa acuminata) and definition of NAC orthologous groups for monocots and dicots. Plant Mol Biol. 2014;85:63-80.

29. Sablowski RWM, Meyerowitz EM. A homolog of NO APICAL MERISTEM is an immediate target of the floral homeotic genes APETALA3/PISTILLATA. Cell. 1998;92:93-103.

30. Aida M, Ishida T, Tasaka M. Shoot apical meristem and cotyledon formation during Arabidopsis embryogenesis: interaction among the
CUP-SHAPED COTYLEDON and SHOOT MERISTEMLESS genes. Development. 1999;126:1563-70.

31. Takada S, Hibara K, Ishida T, Tasaka M. The CUP-SHAPED COTYLEDON1 gene of Arabidopsis regulates shoot apical meristem formation | Development. Development. 2001;128:1127-35. https://dev.biologists.org/ content/128/7/1127. Accessed 26 Sept 2020.

32. Hibara KI, Takada S, Tasaka M. CUC1 gene activates the expression of SAM-related genes to induce adventitious shoot formation. Plant J. 2003:36:687-96.

33. Vroemen CW, Mordhorst AP, Albrecht C, Kwaaitaal MACJ, de Vries SC. The CUP-SHAPED COTYLEDON3 gene is required for boundary and shoot meristem formation in Arabidopsis. Plant Cell. 2003;15:1563-77.

34. Weir I, Lu J, Cook H, Causier B, Schwarz-Sommer Z, Davies B. Cupuliformis establishes lateral organ boundaries in Antirrhinum. Development. 2003;131:915-22. https://doi.org/10.1242/dev.00993.

35. Nikovics K, Blein T, Peaucelle A, Ishida T, Morin H, Aida M, et al. The balance between the MIR164A and CUC2 genes controls leaf margin serration in Arabidopsis. Plant Cell. 2006;18:2929-45.

36. Xie Q, Frugis G, Colgan D, Chua N. Arabidopsis NAC1 transduces auxin signal downstream of TIR1 to promote lateral root development. Genes Dev. 2000;14:3024-36.

37. He XJ, Mu RL, Cao WH, Zhang ZG, Zhang JS, Chen SY. AtNAC2, a transcription factor downstream of ethylene and auxin signaling pathways, is involved in salt stress response and lateral root development. Plant J. 2005:44:903-16.

38. Guo Y, Gan S. AtNAP, a NAC family transcription factor, has an important role in leaf senescence. Plant J. 2006;46:601-12.

39. Uauy C, Distelfeld A, Fahima T, Blechl A, Dubcovsky J. A NAC gene regulating senescence improves grain protein, $\mathrm{Zn}$, and Fe content in wheat. Science (80- ). 2006;314:1298-301.

40. Kjaersgaard T, Jensen MK, Christiansen MW, Gregersen P, Kragelund BB, Skriver K. Senescence-associated barley NAC (NAM, ATAF1,2, CUC) transcription factor interacts with radical-induced cell death 1 through a disordered regulatory domain. J Biol Chem. 2011;286:35418-29.

41. Yang SD, Seo PJ, Yoon HK, Park CM. The arabidopsis NAC transcription factor VNI2 integrates abscisic acid signals into leaf senescence via the COR/RD genes. Plant Cell. 2011;23:2155-68.

42. Lee S, Seo PJ, Lee HJ, Park CM. A NAC transcription factor NTL4 promotes reactive oxygen species production during drought-induced leaf senescence in Arabidopsis. Plant J. 2012;70:831-44.

43. Kou X, Watkins CB, Gan SS. Arabidopsis AtNAP regulates fruit senescence. J Exp Bot. 2012;63:6139-47. https://doi.org/10.1093/jxb/ers266.

44. Fan K, Bibi N, Gan S, Li F, Yuan S, Ni M, et al. A novel NAP member GhNAP is involved in leaf senescence in Gossypium hirsutum. J Exp Bot. 2015;66:4669-82.

45. Podzimska-Sroka D, O'Shea C, Gregersen PL, Skriver K. NAC transcription factors in senescence: from molecular structure to function in crops. Plants. 2015;4:412-48.

46. Takasaki H, Maruyama K, Takahashi F, Fujita M, Yoshida T, Nakashima $\mathrm{K}$, et al. SNAC-As, stress-responsive NAC transcription factors, mediate ABA-inducible leaf senescence. Plant J. 2015:84:1114-23.

47. Pimenta MR, Silva PA, Mendes GC, Alves JR, Caetano HDN, Machado $J P B$, et al. The stress-induced soybean NAC transcription factor GmNAC81 plays a positive role in developmentally programmed leaf senescence. Plant Cell Physiol. 2016:57:1098-114.

48. Mao C, Lu S, Lv B, Zhang B, Shen J, He J, et al. A rice nac transcription factor promotes leaf senescence via ABA biosynthesis. Plant Physiol. 2017:174:1747-63.

49. Li S, Xu H, Ju Z, Cao D, Zhu H, Fu D, et al. The RIN-MC fusion of MADS-box transcription factors has transcriptional activity and modulates expression of many ripening genes 1. Plant Physiol. 2018;176(January):891-909.

50. Ma X, Balazadeh S, Mueller-Roeber B. Tomato fruit ripening factor NOR controls leaf senescence. J Exp Bot. 2019;70:2727-40.

51. Tran LSP, Nishiyama R, Yamaguchi-Shinozaki K, Shinozaki K. Potential utilization of NAC transcription factors to enhance abiotic stress tolerance in plants by biotechnological approach. GM Crops. 2010;1:32-9.

52. Nuruzzaman M, Sharoni AM, Kikuchi S. Roles of NAC transcription factors in the regulation of biotic and abiotic stress responses in plants. Front Microbiol. 2013;4:1-16. 
53. Shao $\mathrm{H}$, Wang $\mathrm{H}$, Tang $X$. NAC transcription factors in plant multiple abiotic stress responses: Progress and prospects. Front Plant Sci. 2015;6:902. https://doi.org/10.3389/fpls.2015.00902.

54. Wang G, Zhang S, Ma X, Wang Y, Kong F, Meng Q. A stress-associated NAC transcription factor (SINAC35) from tomato plays a positive role in biotic and abiotic stresses. Physiol Plant. 2016;158:45-64. https://doi. org/10.1111/ppl.12444.

55. Tweneboah S, Oh SK. Biological roles of NAC transcription factors in the regulation of biotic and abiotic stress responses in solanaceous crops. J Plant Biotechnol. 2017:44:1-11.

56. Baillo EH, Kimotho RN, Zhang Z, Xu P. Transcription factors associated with abiotic and biotic stress tolerance and their potential for crops improvement. Genes (Basel). 2019;10:1-23.

57. Yang X, Kim MY, Ha J, Lee SH. Overexpression of the soybean NAC gene GmNAC109 increases lateral root formation and abiotic stress tolerance in transgenic arabidopsis plants. Front Plant Sci. 2019;10(August):1-12.

58. Yong $Y$, Zhang $Y$, Lyu Y. A stress-responsive NAC transcription factor from tiger lily (LLNAC2) interacts with Ildreb1 and LLZHFD4 and enhances various abiotic stress tolerance in arabidopsis. Int J Mol Sci. 2019;20:1-20.

59. Tran LSP, Nakashima K, Sakuma Y, Simpson SD, Fujita Y, Maruyama K, et al. Isolation and functional analysis of arabidopsis stress-inducible NAC transcription factors that bind to a drought-responsive ciselement in the early responsive to dehydration stress 1 promoter. Plant Cell. 2004;16:2481-98. https://doi.org/10.1105/tpc.104.022699.

60. Bhatnagar-Mathur P, Devi MJ, Reddy DS, Lavanya M, Vadez V, Serraj R, et al. Stress-inducible expression of at DREB1A in transgenic peanut (Arachis hypogaea L.) increases transpiration efficiency under waterlimiting conditions. Plant Cell Rep. 2007;26:2071-82.

61. Gao F, Xiong A, Peng $R$, Jin X, Xu J, Zhu B, et al. OsNAC52, a rice NAC transcription factor, potentially responds to $A B A$ and confers drought tolerance in transgenic plants. Plant Cell Tissue Organ Cult. 2010;100:255-62. https://doi.org/10.1007/s11240-009-9640-9.

62. Nakashima K, Yamaguchi-Shinozaki K, Shinozaki K. The transcriptional regulatory network in the drought response and its crosstalk in abiotic stress responses including drought, cold, and heat. Front Plant Sci. 2014;5(May):1-7.

63. Wang J, Lian W, Cao Y, Wang X, Wang G, Qi C, et al. Overexpression of BoNAC019, a NAC transcription factor from Brassica oleracea, negatively regulates the dehydration response and anthocyanin biosynthesis in Arabidopsis. Sci Rep. 2018;8:1-15. https://doi.org/10.1038/ s41598-018-31690-1.

64. Guérin C, Roche J, Allard V, Ravel C, Mouzeyar S, Bouzidi MF. Genomewide analysis, expansion and expression of the NAC family under drought and heat stresses in bread wheat (T. Aestivum L.). PLoS One. 2019;14:1-26. https://doi.org/10.1371/journal.pone.0213390.

65. Yuan X, Wang H, Cai J, Bi Y, Li D, Song F. Rice NAC transcription factor ONAC066 functions as a positive regulator of drought and oxidative stress response. BMC Plant Biol. 2019;19:1-19.

66. Huang Q, Wang Y, Li B, Chang J, Chen M, Li K, et al. TaNAC29, a NAC transcription factor from wheat, enhances salt and drought tolerance in transgenic Arabidopsis. BMC Plant Biol. 2015;15:1-15. https://doi.org/ 10.1186/s12870-015-0644-9.

67. He Z, Li Z, Lu H, Huo L, Wang Z, Wang Y, et al. The NAC protein from Tamarix hispida, ThNAC7, confers salt and osmotic stress tolerance by increasing reactive oxygen species scavenging capability. Plants. 2019:8:1-19.

68. Nuruzzaman M, Sharoni AM, Satoh K, Karim MR, Harikrishna JA, Shimizu T, et al. NAC transcription factor family genes are differentially expressed in rice during infections with rice dwarf virus, rice blackstreaked dwarf virus, rice grassy stunt virus, rice ragged stunt virus, and rice transitory yellowing virus. Front Plant Sci. 2015;6(September):1-15.

69. Zhang H, Lv S, Wang C, Ji W. The role of transcription factor in wheat defense against pathogen and its prospect in breeding. J Plant Biol Crop Res. 2018;1. https://www.meddocsonline.org/journal-of-plantbiology-and-crop-research/The-role-of-transcription-factor-inwheat-defense-against-pathogen-and-its-prospect-in-breeding.html. Accessed 29 Sept 2020.

70. Meisrimler CN, Pelgrom AJE, Oud B, Out S, Van den Ackerveken G. Multiple downy mildew effectors target the stress-related NAC transcription factor LsNAC069 in lettuce. Plant J. 2019;99:1098-115.
71. Yuan X, Wang H, Cai J, Li D, Song F. NAC transcription factors in plant immunity. Phytopathol Res. 2019;1:1-13.

72. Ko JH, Yang SH, Park AH, Lerouxel O, Han KH. ANAC012, a member of the plant-specific NAC transcription factor family, negatively regulates xylary fiber development in Arabidopsis thaliana. Plant J. 2007;50:1035-48.

73. Sun H, Hu M, Li J, Chen L, Li M, Zhang S, et al. Comprehensive analysis of NAC transcription factors uncovers their roles during fiber development and stress response in cotton. BMC Plant Biol. 2018:18:1-15.

74. Chai M, Bellizzi M, Wan C, Cui Z, Li Y, Wang GL. The NAC transcription factor OsSWN1 regulates secondary cell wall development in Oryza sativa. J Plant Biol. 2015;58:44-51. https://doi.org/10.1007/ s12374-014-0400-y.

75. Nakano Y, Yamaguchi M, Endo H, Rejab NA, Ohtani M. NAC-MYB-based transcriptional regulation of secondary cell wall biosynthesis in land plants. Front Plant Sci. 2015;6:288. https://doi.org/10.3389/fpls.2015. 00288.

76. Mitsuda N, Ohme-Takagi M. NAC transcription factors NST1 and NST3 regulate pod shattering in a partially redundant manner by promoting secondary wall formation after the establishment of tissue identity. Plant J. 2008;56:768-78. https://doi.org/10.1111/j.1365-313X.2008. 03633.x.

77. Zhang H, Ying YQ, Wang J, Zhao XH, Zeng W, Beahan C, et al. Transcriptome analysis provides insights into xylogenesis formation in Moso bamboo (Phyllostachys edulis) shoot. Sci Rep. 2018;8:1-16. https://doi. org/10.1038/s41598-018-21766-3.

78. Yang Y, Yoo CG, Rottmann W, Winkeler KA, Collins CM, Gunter LE, et al. PdWND3A, a wood-associated NAC domain-containing protein, affects lignin biosynthesis and composition in Populus. BMC Plant Biol. 2019;19:1-12.

79. Yu Y. OsKNAT7 bridges secondary cell wall formation and cell growth regulation. Plant Physiol. 2019;181:385-6.

80. McCarthy RL, Zhong R, Ye ZH. Secondary wall NAC binding element (SNBE), a key Cis-acting element required for target gene activation by secondary wall NAC master switches. Plant Signal Behav. 2011;6:1282-5.

81. Zhong R, Lee C, Ye ZH. Global analysis of direct targets of secondary wall NAC master switches in arabidopsis. Mol Plant. 2010;3:1087-103.

82. Jensen MK, Kjaersgaard T, Petersen K, Skriver K. NAC genes: time-specific regulators of hormonal signaling in Arabidopsis. Plant Signal Behav. 2010;5:907-10.

83. Ma X, Zhang Y, Turečková $V$, Xue GP, Fernie AR, Mueller-Roeber B, et al. The NAC transcription factor SLNAP2 regulates leaf senescence and fruit yield in tomato. Plant Physiol. 2018;177:1286-302.

84. Kou X, Zhou J, Wu CE, Yang S, Liu Y, Chai L, et al. The interplay between ABA/ethylene and NAC TFs in tomato fruit ripening: a review. Plant Mol Biol. 2021;1:3. https://doi.org/10.1007/s11103-021-01128-w.

85. Kim YS, Kim SG, Park JE, Park HY, Lim MH, Chua NH, et al. A membranebound NAC transcription factor regulates cell division in Arabidopsis. Plant Cell. 2006;18:3132-44.

86. Bu Q, Jiang H, Li CB, Zhai Q, Zhang J, Wu X, et al. Role of the Arabidopsis thaliana NAC transcription factors ANAC019 and ANAC055 in regulating jasmonic acid-signaled defense responses. Cell Res. 2008;18:756-67. https://doi.org/10.1038/cr.2008.53.

87. Shahnejat-Bushehri S, Tarkowska D, Sakuraba Y, Balazadeh S. Arabidopsis NAC transcription factor JUB1 regulates GA/BR metabolism and signalling. Nat Plants. 2016;2:1-9. https://doi.org/10.1038/NPLANTS. 2016.13.

88. Shahnejat-Bushehri S, Allu AD, Mehterov N, Thirumalaikumar VP, Alseekh S, Fernie AR, et al. Arabidopsis NAC transcription factor JUNGBRUNNEN1 exerts conserved control over gibberellin and brassinosteroid metabolism and signaling genes in tomato. Front Plant Sci. 2017:8:1-13.

89. Johnsson C, Jin X, Xue W, Dubreuil C, Lezhneva L, Fischer U. The plant hormone auxin directs timing of xylem development by inhibition of secondary cell wall deposition through repression of secondary wall NAC-domain transcription factors. Physiol Plant. 2019;165:673-89. https://doi.org/10.1111/ppl.12766.

90. Ernst HA, Olsen AN, Skriver K, Larsen S, Lo LL. Structure of the conserved domain of ANAC, a member of the NAC family of transcription factors. EMBO Rep. 2004:5:297-303. 
91. Olsen AN, Ernst HA, Leggio LL, Skriver K. NAC transcription factors: Structurally distinct, functionally diverse. Trends Plant Sci. 2005:10:79-87.

92. Kikuchi K, Ueguchi-Tanaka M, Yoshida KT, Nagato Y, Matsusoka M, Hirano HY. Molecular analysis of the NAC gene family in rice. Mol Gen Genet. 2000;262:1047-51. https://doi.org/10.1007/PL00008647.

93. Duval M, Hsieh TF, Kim SY, Thomas TL. Molecular characterization of AtNAM: a member of the Arabidopsis NAC domain superfamily. Plant Mol Biol. 2002:50:237-48. https://doi.org/10.1023/A:1016028530943.

94. Chen Q, Wang Q, Xiong L, Lou Z. A structural view of the conserved domain of rice stress-responsive NAC1. Protein Cell. 2011;2:55-63. https://doi.org/10.1007/s13238-011-1010-9.

95. Welner DH, Lindemose S, Grossmann JG, Møllegaard NE, Olsen AN, Helgstrand C, et al. DNA binding by the plant-specific NAC transcription factors in crystal and solution: a firm link to WRKY and GCM transcription factors. Biochem J. 2012:444:395-404. https://doi.org/10.1042/ BJ20111742.

96. Hao YJ, Song QX, Chen HW, Zou HF, Wei W, Kang XS, et al. Plant NACtype transcription factor proteins contain a NARD domain for repression of transcriptional activation. Planta. 2010:232:1033-43.

97. Jensen MK, Skriver K. NAC transcription factor gene regulatory and protein-protein interaction networks in plant stress responses and senescence. IUBMB Life. 2014;66:156-66. https://doi.org/10.1002/iub. 1256.

98. Gómez MD, Vera-Sirera F, Pérez-Amador MA. Molecular programme of senescence in dry and fleshy fruits. J Exp Bot. 2014;65:4515-26.

99. Kunieda T, Mitsuda N, Ohme-Takagi M, Takeda S, Aida M, Tasaka M, et al. NAC family proteins NARS1/NAC2 and NARS2/NAM in the outer integument regulate embryogenesis in arabidopsis. Plant Cell. 2008;20:263142. https://doi.org/10.1105/tpc.108.060160.

100. Tigchelaar E, Tomes M, Kerr E, Barman R. A new fruit ripening mutant, nonripening (nor). Rep Tomato Genet Coop. 1973;23:33-4.

101. Mizzotti C, Rotasperti L, Moretto M, Tadini L, Resentini F, Galliani BM, et al. Time-course transcriptome analysis of arabidopsis siliques discloses genes essential for fruit development and maturation. Plant Physiol. 2018;178:1249-68. https://doi.org/10.1104/pp.18.00727.

102. Sato S, Tabata S, Hirakawa H, Asamizu E, Shirasawa K, Isobe S, et al. The tomato genome sequence provides insights into fleshy fruit evolution. Nature. 2012;485:635-41.

103. Sakuraba Y, Kim Y-S, Han S-H, Lee B-D, Paek N-C. The Arabidopsis transcription factor NAC016 promotes drought stress responses by repressing AREB1 transcription through a trifurcate feed-forward regulatory loop involving NAP. Plant Cell. 2015;27:1771-87. https://doi.org/ 10.1105/tpc.15.00222.

104. Tigchelaar EC, McGlasson WB, Franklin MJ. Natural and ethephon stimulated ripening of $\mathrm{F} 1$ hybrids of the ripening inhibitor (rin) and non-ripening (nor) mutants of tomato (Lycopersicon esculentum Mill.). Aust J Plant Physiol. 1978;5:449-56. https://agris.fao.org/agris-search/ search.do?recordID=AU7901714. Accessed 15 Oct 2020.

105. Klee HJ, Giovannoni JJ. Genetics and control of tomato fruit ripening and quality attributes. Annu Rev Genet. 2011;45:41-59. https://doi.org/ 10.1146/annurev-genet-110410-132507.

106. Karlova R, Chapman N, David K, Angenent GC, Seymour GB, De Maagd RA. Transcriptional control of fleshy fruit development and ripening. J Exp Bot. 2014:65:4527-41.

107. Casals J, Pascual L, Cañizares J, Cebolla-Cornejo J, Casañas F, Nuez F. Genetic basis of long shelf life and variability into Penjar tomato. Genet Resour Crop Evol. 2012;59:219-29.

108. Kumar R, Tamboli V, Sharma R, Sreelakshmi Y. NAC-NOR mutations in tomato Penjar accessions attenuate multiple metabolic processes and prolong the fruit shelf life. Food Chem. 2018;259:234-44. https://doi. org/10.1016/j.foodchem.2018.03.135.

109. Gao Y, Zhu N, Zhu X, Wu M, Cai-Zhong J, Grierson D, et al. Diversity and redundancy of the ripening regulatory networks revealed by the fruitENCODE and the new CRISPR/Cas9 CNR and NOR mutants. Hortic Res. 2019;6:39.

110. Wang R, da Rocha Tavano EC, Lammers M, Martinelli AP, Angenent GC, de Maagd RA. Re-evaluation of transcription factor function in tomato fruit development and ripening with CRISPR/Cas9-mutagenesis. Sci Rep. 2019:9:1-10.
111. Wang R, Angenent GC, Seymour G, de Maagd RA. Revisiting the role of master regulators in tomato ripening. Trends Plant Sci. 2020;25:291301. https://doi.org/10.1016/j.tplants.2019.11.005.

112. Gao Y, Wei W, Fan Z, Zhao X, Zhang Y, Jing Y, et al. Re-evaluation of the nor mutation and the role of the NAC-NOR transcription factor in tomato fruit ripening. J Exp Bot. 2020;71:3560-74.

113. Ito Y, Sekiyama Y, Nakayama H, Nishizawa-Yokoi A, Endo M, Shima Y, et al. Allelic mutations in the ripening -inhibitor locus generate extensive variation in tomato ripening. Plant Physiol. 2020;183:80-95.

114. Giovannoni JJ. Genetic regulation of fruit development and ripening. Plant Cell. 2004;16(SUPPL.):S170-80. https://doi.org/10.1105/tpc.019158.

115. Barry CS, Giovannoni JJ. Ethylene and fruit ripening. J Plant Growth Regul. 2007;26:143-59.

116. Martel C, Vrebalov J, Tafelmeyer P, Giovannoni JJ. The tomato MADS-box transcription factor RIPENING INHIBITOR interacts with promoters involved in numerous ripening processes in a COLORLESS NONRIPENING-dependent manner. Plant Physiol. 2011;157:1568-79.

117. Fujisawa M, Nakano T, Shima Y, Ito Y. A large-scale identification of direct targets of the tomato MADS box transcription factor RIPENING INHIBITOR reveals the regulation of fruit ripening. Plant Cell. 2013:25:371-86.

118. Fujisawa M, Shima Y, Higuchi N, Nakano T, Koyama Y, Kasumi T, et al. Direct targets of the tomato-ripening regulator RIN identified by transcriptome and chromatin immunoprecipitation analyses. Planta. 2012;235:1107-22. https://doi.org/10.1007/s00425-011-1561-2.

119. Wang R, Lammers M, Tikunov Y, Bovy AG, Angenent GC, de Maagd RA. The rin, nor and $\mathrm{Cnr}$ spontaneous mutations inhibit tomato fruit ripening in additive and epistatic manners. Plant Sci. 2020;294:1-12. https:// doi.org/10.1016/j.plantsci.2020.110436.

120. Cantu D, Blanco-Ulate B, Yang L, Labavitch JM, Bennett AB, Powell ALT. Ripening-regulated susceptibility of tomato fruit to Botrytis cinerea requires NOR but not RIN or Ethylene. Plant Physiol. 2009:150:1434-49.

121. Jin JF, Wang ZQ, He QY, Wang JY, Li PF, Xu JM, et al. Genome-wide identification and expression analysis of the NAC transcription factor family in tomato (Solanum lycopersicum) during aluminum stress. BMC Genomics. 2020;21:1-14.

122. Han Q, Zhang J, Li H, Luo Z, Ziaf K, Ouyang B, et al. Identification and expression pattern of one stress-responsive NAC gene from Solanum lycopersicum. Mol Biol Rep. 2012;39:1713-20.

123. Han QQ, Song YZ, Zhang JY, Liu LF. Studies on the role of the SINAC3 gene in regulating seed development in tomato (Solanum lycopersicum). J Hortic Sci Biotechnol. 2014;89:423-9.

124. Jing L, Li J Song Y, Zhang J, Chen $\mathrm{O}$, Han $\mathrm{O}$. Characterization of a potential ripening regulator, SINAC3, from Solanum lycopersicum. Open Life Sci. 2018;13:518-26.

125. Zhu M, Chen G, Zhang J, Zhang Y, Xie Q, Zhao Z, et al. The abiotic stress-responsive NAC-type transcription factor SINAC4 regulates salt and drought tolerance and stress-related genes in tomato (Solanum lycopersicum). Plant Cell Rep. 2014;33:1851-63.

126. Zhu M, Chen G, Zhou S, Tu Y, Wang Y, Dong T, et al. A new tomato NAC (NAM ATAF1/2/CUC2) transcription factor, SINAC4, functions as a positive regulator of fruit ripening and carotenoid accumulation. Plant Cell Physiol. 2014;55:119-35.

127. Kou X, Liu C, Han L, Wang S, Xue Z. NAC transcription factors play an important role in ethylene biosynthesis, reception and signaling of tomato fruit ripening. Mol Genet Genomics. 2016;291:1205-17.

128. Li S, Gao J, Yao L, Ren G, Zhu X, Gao S, et al. The role of ANAC072 in the regulation of chlorophyll degradation during age- and dark-induced leaf senescence. Plant Cell Rep. 2016;35:1729-41. https://doi.org/10. 1007/s00299-016-1991-1.

129. Gao Y, Wei W, Zhao X, Tan X, Fan Z, Zhang Y, et al. A NAC transcription factor, NOR-like1, is a new positive regulator of tomato fruit ripening. Hortic Res. 2018:5:75

130. Ma NN, Zuo YQ, Liang XQ, Yin B, Wang GD, Meng QW. The multiple stress-responsive transcription factor SINAC1 improves the chilling tolerance of tomato. Physiol Plant. 2013;149:474-86.

131. Liang XQ, Ma NN, Wang GD, Meng X, Ai XZ, Meng OW. Suppression of SINAC1 reduces heat resistance in tomato plants. Biol Plant. 2014;59:92-8

132. Huang W, Miao M, Kud J, Niu X, Ouyang B, Zhang J, et al. SINAC1, a stress-related transcription factor, is fine-tuned on both the transcriptional and the post-translational level. New Phytol. 2013;197:1214-24. 
133. Ma N, Feng H, Meng X, Li D, Yang D, Wu C, et al. Overexpression of tomato SINAC 1 transcription factor alters fruit pigmentation and softening. BMC Plant Biol. 2014;14:1-14.

134. Meng C, Yang D, Ma X, Zhao W, Liang X, Ma N, et al. Suppression of tomato SINAC 1 transcription factor delays fruit ripening. J Plant Physiol. 2016;193:88-96. https://doi.org/10.1016/j.jplph.2016.01.014

135. Lira BS, Gramegna G, Trench BA, Alves FRR, Silva EM, Silva GFF, et al. Manipulation of a senescence-associated gene improves fleshy fruit yield. Plant Physiol. 2017;175:77-91. https://doi.org/10.1104/pp.17. 00452.

136. Oh SA, Park J, In Lee G, Hee Paek K, Ki Park S, Gil NH. Identification of three genetic loci controlling leaf senescence in Arabidopsis thaliana. Plant J. 1997;12:527-35.

137. Kou X, Zhao Y, Wu C, Jiang B, Zhang Z, Rathbun JR, et al. SNAC4 and SNAC 9 transcription factors show contrasting effects on tomato carotenoids biosynthesis and softening. Postharvest Biol Technol. 2018;144:9-19.

138. Quinet M, Angosto T, Yuste-Lisbona FJ, Blanchard-Gros R, Bigot S, Martinez JP, et al. Tomato fruit development and metabolism. Front Plant Sci. 2019:10:1-23.

139. Nuruzzaman M, Manimekalai R, Sharoni AM, Satoh K, Kondoh H, Ooka $\mathrm{H}$, et al. Genome-wide analysis of NAC transcription factor family in rice. Gene. 2010;465:30-44. https://doi.org/10.1016/j.gene.2010.06.008.

140. Murozuka E, Massange-Sánchez JA, Nielsen K, Gregersen PL, Braumann I. Genome wide characterization of barley NAC transcription factors enables the identification of grain-specific transcription factors exclusive for the Poaceae family of monocotyledonous plants. PLoS One. 2018;13:1-28

141. Sharma R, Agarwal P, Ray S, Deveshwar P, Sharma P, Sharma N, et al. Expression dynamics of metabolic and regulatory components across stages of panicle and seed development in indica rice. Funct Integr Genomics. 2012;12:229-48. https://doi.org/10.1007/s10142-012-0274-3.

142. Mathew IE, Das S, Mahto A, Agarwal P. Three rice NAC transcription factors heteromerize and are associated with seed size. Front Plant Sci. 2016;2016(7):1-16.

143. Ren $Y$, Huang $Z$, Jiang $H$, Wang $Z$, Wu F, Xiong $Y$, et al. A heat stress responsive NAC transcription factor heterodimer plays key roles in rice caryopsis filling. bioRxiv. 2020. https://doi.org/10.1101/2020.02.08. 939728.

144. Jeong JS, Kim YS, Baek KH, Jung H, Ha SH, Do Choi Y, et al. Root-specific expression of OsNAC10 improves drought tolerance and grain yield in rice under field drought conditions. Plant Physiol. 2010;153:185-97.

145. Redillas MCFR, Jeong JS, Kim YS, Jung H, Bang SW, Choi YD, et al. The overexpression of OsNAC9 alters the root architecture of rice plants enhancing drought resistance and grain yield under field conditions. Plant Biotechnol J. 2012;10:792-805. https://doi.org/10.1111/j.14677652.2012.00697x.

146. Jeong JS, Kim YS, Redillas MCFR, Jang G, Jung H, Bang SW, et al. OsNAC5 overexpression enlarges root diameter in rice plants leading to enhanced drought tolerance and increased grain yield in the field. Plant Biotechnol J. 2013:11:101-14

147. Hu H, Dai M, Yao J, Xiao B, Li X, Zhang Q, et al. Overexpressing a NAM, ATAF, and CUC (NAC) transcription factor enhances drought resistance and salt tolerance in rice. Proc Natl Acad Sci U S A. 2006;103:12987-92. https://doi.org/10.1073/pnas.0604882103.

148. Chen M, MacGregor DR, Dave A, Florance H, Moore K, Paszkiewicz K, et al. Maternal temperature history activates flowering locus $\mathrm{T}$ in fruits to control progeny dormancy according to time of year. Proc Natl Acad Sci U S A. 2014;111:18787-92. https://doi.org/10.1073/pnas.14122 74111.

149. Hong Y, Zhang H, Huang L, Li D, Song F. Overexpression of a stressresponsive NAC transcription factor gene ONAC022 improves drought and salt tolerance in rice. Front Plant Sci. 2016;7:1-19.

150. Mao C, Ding W, Wu Y, Yu J, He X, Shou H, et al. Overexpression of a NAC-domain protein promotes shoot branching in rice. New Phytol. 2007:176:288-98.

151. Chen X, Lu S, Wang Y, Zhang X, Lv B, Luo L, et al. OsNAC2 encoding a NAC transcription factor that affects plant height through mediating the gibberellic acid pathway in rice. Plant J. 2015;82:302-14.
152. Jiang D, Chen W, Dong J, Li J, Yang F, Wu Z, et al. Overexpression of miR164b-resistant OsNAC2 improves plant architecture and grain yield in rice. J Exp Bot. 2018;69:1533-43.

153. Wang A, Xu K. Characterization of two orthologs of REVERSION-TOETHYLENE SENSITIVITY1 in apple. J Mol Biol Res. 2012;2:24-41.

154. Jia D, Gong X, Li M, Li C, Sun T, Ma F. Overexpression of a novel apple NAC transcription factor gene, MdNAC1, confers the dwarf phenotype in transgenic apple (Malus domestica). Genes (Basel). 2018;9:229. https://doi.org/10.3390/genes9050229.

155. Jia D, Jiang Q, van Nocker S, Gong X, Ma F. An apple (Malus domestica) NAC transcription factor enhances drought tolerance in transgenic apple plants. Plant Physiol Biochem. 2019;139(March):504-12. https:// doi.org/10.1016/j.plaphy.2019.04.011.

156. Busatto N, Tadiello A, Trainotti L, Costa F. Climacteric ripening of apple fruit is regulated by transcriptional circuits stimulated by cross-talks between ethylene and auxin. Plant Signal Behav. 2017;12:1-4. https:// doi.org/10.1080/15592324.2016.1268312.

157. Zhang Q, LiT, Zhang L, Dong W, Wang A. Expression analysis of NAC genes during the growth and ripening of apples. Hortic Sci. 2018:45:1-10

158. An JP, Yao JF, Xu RR, You CX, Wang XF, Hao YJ. An apple NAC transcription factor enhances salt stress tolerance by modulating the ethylene response. Physiol Plant. 2018;164:279-89.

159. Li H, Ran K, Dong Q, Zhao Q, Shi S. Cloning, sequencing, and expression analysis of 32 NAC transcription factors (MdNAC) in apple. PeerJ. 2020;8:e8249. https://doi.org/10.7717/peerj.8249.

160. Larsen B, Migicovsky Z, Jeppesen AA, Gardner KM, Toldam-Andersen TB, Myles S, et al. Genome-wide association studies in apple reveal loci for aroma volatiles, sugar composition, and harvest date. Plant Genome. 2019;12:180104.

161. Yeats T, Migicovsky Z, Watts S, Song J, Forney C, Burgher-MacLellan K, et al. Allelic diversity of NAC18.1 is a major determinant of fruit firmness and harvest date in apple (Malus domestica ). bioRxiv. 2019. https://doi. org/10.1101/708040.

162. Schaefer HM, Schaefer V, Levey DJ. How plant-animal interactions signal new insights in communication. Trends Ecol Evol. 2004;19:577-84.

163. Sun Q, Jiang S, Zhang $T, X u H$, Fang H, Zhang J, et al. Apple NAC transcription factor MdNAC52 regulates biosynthesis of anthocyanin and proanthocyanidin through MdMYB9 and MdMYB11. Plant Sci. 2019;289(June):110286. https://doi.org/10.1016/j.plantsci.2019.110286.

164. Zhang S, Chen Y, Zhao L, Li C, Yu J, Li T, et al. A novel NAC transcription factor, MdNAC42, regulates anthocyanin accumulation in red-fleshed apple by interacting with MdMYB10. Tree Physiol. 2020;40:413-23.

165. Moyano E, Martínez-Rivas FJ, Blanco-Portales R, Molina-Hidalgo FJ, RicVaras P, Matas-Arroyo AJ, et al. Genome-wide analysis of the NAC transcription factor family and their expression during the development and ripening of the Fragaria $\times$ ananassa fruits. PLoS One. 2018;13:1-23.

166. Lin Y, Jiang L, Chen Q, Li Y, Zhang Y, Luo Y, et al. Comparative transcriptome profiling analysis of red-and white-fleshed strawberry (Fragaria $X$ ananassa) provides new insight into the regulation of the anthocyanin pathway. Plant Cell Physiol. 2018;59:1844-59.

167. Moya-León MA, Mattus-Araya E, Herrera R. Molecular events occurring during softening of strawberry fruit. Front Plant Sci. 2019;10(May):1-11.

168. Martín-Pizarro C, Vallarino JG, Osorio S, Meco V, Urrutia M, Pillet J, et al. The NAC transcription factor FaRIF controls fruit ripening in strawberry. Plant Cell. 2021. https://doi.org/10.1093/plcell/koab070.

169. Xu X, Yin L, Ying Q, Song H, Xue D, Lai T, et al. High-throughput sequencing and degradome analysis identify miRNAs and their targets involved in fruit senescence of Fragaria ananassa. PLoS One. 2013;8:e70959. https://doi.org/10.1371/journal.pone.0070959.

170. Kim JH, Woo HR, Kim J, Lim PO, Lee IC, Choi SH, et al. Trifurcate feedforward regulation of age-dependent cell death involving miR164 in Arabidopsis. Science (80- ). 2009;323:1053-7. https://doi.org/10.1126/ science.1166386.

171. Li J, Lai T, Song H, Xu X. MiR164 is involved in delaying senescence of strawberry (Fragaria ananassa) fruit by negatively regulating NAC transcription factor genes under low temperature. Russ J Plant Physiol. 2017;64:251-9

172. Wang Y, Li W, Chang H, Zhou J, Luo Y, Zhang K, et al. SRNAome and transcriptome analysis provide insight into strawberry fruit ripening. 
Genomics. 2020;112:2369-78. https://doi.org/10.1016/j.ygeno.2020.01. 008.

173. Carrasco-Orellana C, Stappung Y, Mendez-Yañez A, Allan AC, Espley RV, Plunkett BJ, et al. Characterization of a ripening-related transcription factor FcNAC1 from Fragaria chiloensis fruit. Sci Rep. 2018;8:1-12.

174. Wu J, Fu L, Yi H. Genome-wide identification of the transcription factors involved in citrus fruit ripening from the transcriptomes of a late-ripening sweet orange mutant and its wild type. PLoS One. 2016;11:1-22.

175. Fujita M, Fujita Y, Maruyama K, Seki M, Hiratsu K, Ohme-Takagi M, et al. A dehydration-induced NAC protein, RD26, is involved in a novel ABAdependent stress-signaling pathway. Plant J. 2004;39:863-76. https:// doi.org/10.1111/j.1365-313X.2004.02171.X.

176. Kamranfar I, Xue GP, Tohge T, Sedaghatmehr M, Fernie AR, Balazadeh $S$, et al. Transcription factor RD26 is a key regulator of metabolic reprogramming during dark-induced senescence. New Phytol. 2018;218:1543-57.

177. Liu YZ, Baig MNR, Fan R, Ye JL, Cao YC, Deng XX. Identification and expression pattern of a novel NAM, ATAF, and CUC-like gene from citrus sinensis osbeck. Plant Mol Biol Rep. 2009;27:292-7.

178. Li SJ, Yin XR, Wang WL, Liu XF, Zhang B, Chen KS. Citrus CitNAC62 cooperates with CitWRKY1 to participate in citric acid degradation via up-regulation of CitAco3. J Exp Bot. 2017;68:3419-26.

179. Fan J, Gao X, Yang YW, Deng W, Li ZG. Molecular cloning and characterization of a NAC-like gene in "navel" orange fruit response to postharvest stresses. Plant Mol Biol Rep. 2007;25:145-53. https://doi.org/10.1007/ s11105-007-0016-1.

180. Crifò T, Petrone G, Lo Cicero L, Lo Piero AR. Short cold storage enhances the anthocyanin contents and level of transcripts related to their biosynthesis in blood oranges. J Agric Food Chem. 2012;60:476-81.

181. Mitalo OW, Otsuki T, Okada R, Obitsu S, Masuda K, Hojo Y, et al. Low temperature modulates natural peel degreening in lemon fruit independently of endogenous ethylene. J Exp Bot. 2020;71:4778-96. https://doi.org/10.1093/jxb/eraa206.

182. Martinelli F, Uratsu SL, Albrecht U, Reagan RL, Phu ML, Britton M, et al. Transcriptome profiling of citrus fruit response to huanglongbing disease. PLoS One. 2012;7:1-16.

183. de Oliveira TM, Cidade LC, Gesteira AS, Filho MAC, Filho WSS, Costa MGC. Analysis of the NAC transcription factor gene family in citrus reveals a novel member involved in multiple abiotic stress responses. Tree Genet Genomes. 2011;7:1123-34.

184. Li B, Fan R, Yang Q, Hu C, Sheng O, Deng G, et al. Genome-wide identification and characterization of the NAC transcription factor family in Musa acuminata and expression analysis during fruit ripening. Int J Mol Sci. 2020;21:1-19.

185. Shan W, Kuang JF, Lu WJ, Chen JY. Banana fruit NAC transcription factor MaNAC1 is a direct target of MalCE1 and involved in cold stress through interacting with MaCBF1. Plant Cell Environ. 2014:37:2116-27.

186. Shan W, Kuang J, Chen L, Xie H, Peng H, Xiao Y, et al. Molecular characterization of banana NAC transcription methylation and chromatin patterning factors and their interactions with ethylene signalling component EIL during fruit ripening. J Exp Bot. 2012:63:5175-8.

187. Shan W, Chen JY, Kuang JF, Lu WJ. Banana fruit NAC transcription factor MaNAC5 cooperates with MaWRKYs to enhance the expression of pathogenesis-related genes against Colletotrichum musae. Mol Plant Pathol. 2016;17:330-8.

188. Tak H, Negi S, Gupta A, Ganapathi TR. A stress associated NAC transcription factor MpSNAC67 from banana (Musa x paradisiaca) is involved in regulation of chlorophyll catabolic pathway. Plant Physiol Biochem. 2018;132(August):61-71. https://doi.org/10.1016/j.plaphy.2018.08.020.

189. Tak H, Negi S, Ganapathi TR. Banana NAC transcription factor MusaNAC042 is positively associated with drought and salinity tolerance. Protoplasma. 2017;254:803-16.

190. Negi S, Tak H, Ganapathi TR. A banana NAC transcription factor (MusaSNAC1) impart drought tolerance by modulating stomatal closure and H2O2 content. Plant Mol Biol. 2018;96:457-71. https://doi.org/10.1007/ s11103-018-0710-4.

191. Singh S, Koyama H, Bhati KK, Alok A. The biotechnological importance of the plant-specific NAC transcription factor family in crop improvement. J Plant Res. 123AD;1:3. https://doi.org/10.1007/ s10265-021-01270-y.

\section{Publisher's Note}

Springer Nature remains neutral with regard to jurisdictional claims in published maps and institutional affiliations.
Ready to submit your research? Choose BMC and benefit from:

- fast, convenient online submission

- thorough peer review by experienced researchers in your field

- rapid publication on acceptance

- support for research data, including large and complex data types

- gold Open Access which fosters wider collaboration and increased citations

- maximum visibility for your research: over $100 \mathrm{M}$ website views per year

At BMC, research is always in progress.

Learn more biomedcentral.com/submissions 